\title{
Conceito de Responsabilidade Social de Gestores e Empregados
}

\author{
Concept Of Social Responsability \\ Of Administrators And Employees
}

Concepto De Responsabilidad Social De Administradores Y Empleados

José Fernando Bitencourt Lomônaco, Caio Parada Cabral, Carla Ulasowicz, Patrícia Thomasio Quinelato, Paula Alejandra Boero Villagran \& Tereza Cristina Rangel Credidio Zampieri Universidade de São Paulo
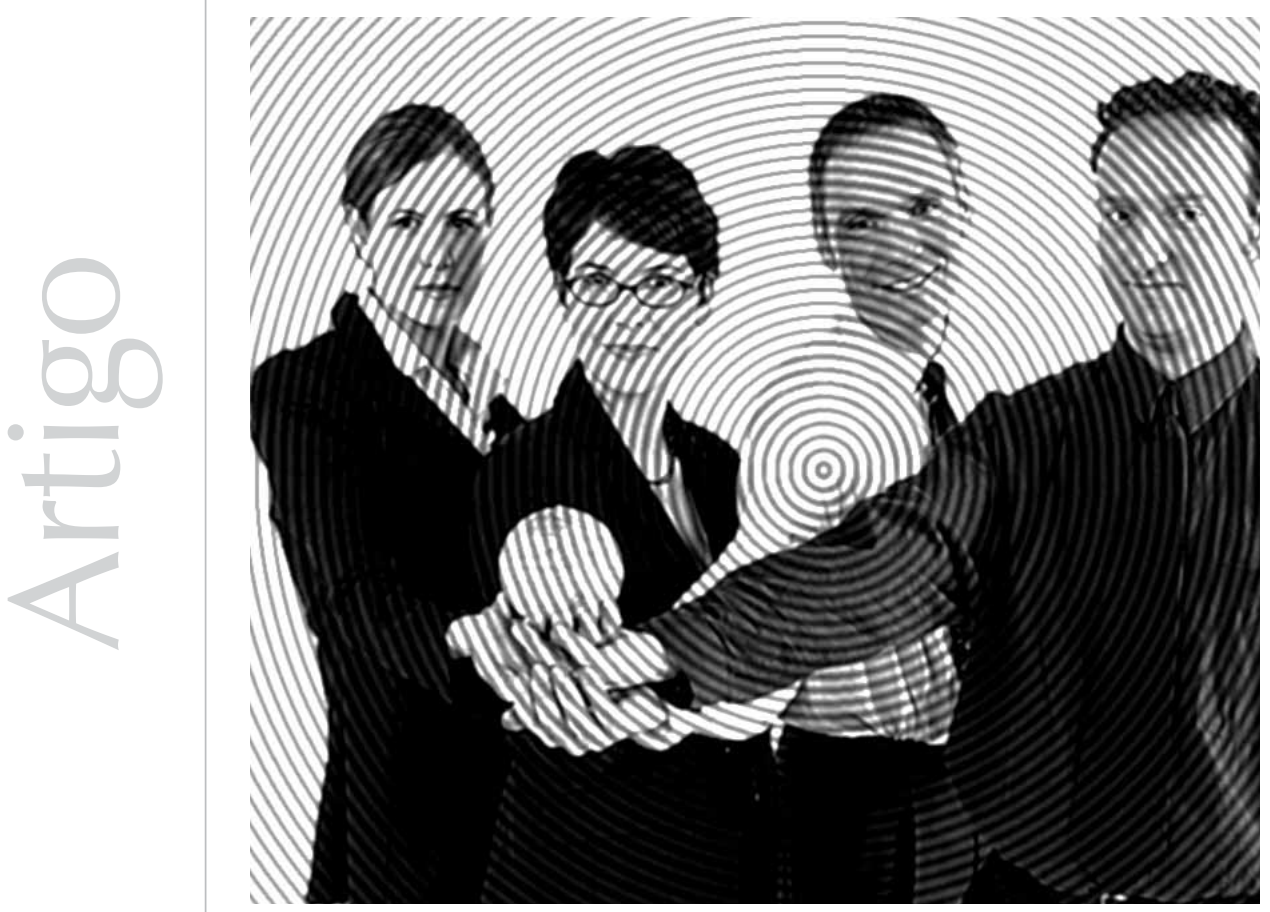
Resumo: Este trabalho visou a avaliar a concepção de responsabilidade social de gestores e empregados de algumas empresas que participam da Política Nacional de Integração da Pessoa com Deficiência. A amostra foi constituída por 57 sujeitos, divididos em dois grupos: gestores e empregados. O grupo de gestores foi formado por 19 profissionais de recursos humanos, e o grupo de empregados, por 38 profissionais com deficiência. Os sujeitos foram solicitados a escrever as associações evocadas pelas palavras responsabilidade social em um período de 90 segundos. A partir dos dados coletados, as respostas dos sujeitos foram agrupadas em oito categorias: preocupação com o ambiente, inclusão social, solidariedade, respeito, compromisso social, sentimentos e atitudes positivos, coletividade e outras respostas. A análise estatística do Qui-quadrado permitiu rejeitar a hipótese nula com um alto grau de probabilidade. Verificou-se que o maior número de respostas associadas ao conceito de responsabilidade social concentrou-se nas categorias inclusão social, sentimentos/atitudes positivos e preocupação com o meio ambiente que, em conjunto, englobaram pouco mais da metade (52\%) do total das respostas. A fim de avaliar o grau de associação entre as respostas dos gestores e dos empregados, foi calculado o coeficiente de correlação posto-ordem de Spearman. Os resultados permitiram identificar uma rede de conceitos associados ao conceito de responsabilidade social, tal como previsto por uma das teorias sobre formação de conceitos: a visão teórica.

Palavras-chave: Formação de conceitos. Deficientes. Inclusão social. Responsabilidade social.

Abstract: This research evaluated the conception of social responsibility of employees and administrators from some companies that participate in the National Politics of Integration of the Person with Disability. The subjects were 57 people divided into two groups: employees and administrators. The group of administrators was formed by 19 professionals of human resources and the group of employees was formed by 38 professionals with disability. The subjects were asked to write associations related to social responsibility in 90 seconds. The responses were grouped in eight categories: concern about the environment, social inclusion, solidarity, respect, social compromise, positive feelings and attitudes, collectivity and other responses. The Chi-squared statistical analysis allowed the rejection of the null hypothesis with a high level of probability. It was checked that the bigger number of responses related to the concept of social responsibility was concentrated in social inclusion, positive feelings and attitudes and concern about the environment categories that, together, represented a little more than the half (52\%) of the total responses. Aiming to evaluate the association degree between the administrators' and the employees' responses the Spearman's rank-order correlation coefficient was calculated. The results allowed the identification of a net of concepts related to the concept of social responsibility, as it was foreseen by one of the theories of concept formation: the theoretical vision.

Keywords: Concept formation. Disabled. Social inclusion. Social responsability of business.

Resumen: El objetivo de este trabajo fue evaluar el concepto de responsabilidad social de empleados y administradores de algunas empresas que participan de la Política Nacional de Integración de la Persona con Deficiencia. La muestra estuvo compuesta por 57 sujetos, divididos en dos grupos: administradores y empleados. El grupo de administradores estuvo constituido por 19 profesionales del área de recursos humanos y el grupo de empleados por 38 profesionales con deficiencia. Se solicitó a los sujetos escribir las asociaciones evocadas por la palabra responsabilidad social en un periodo de tiempo de 90 segundos. Las respuestas de los sujetos fueron agrupadas en ocho categorías: preocupación con el medio ambiente, inclusión social, solidaridad, respeto, compromiso social, sentimientos y actitudes positivas, colectividad e otras respuestas. El análisis estadístico Chi cuadrado permitió rechazar la hipótesis nula en una alta probabilidad. Se verificó que el mayor número de respuestas asociadas al concepto de responsabilidad social (52\%) se concentraron en las categorías: inclusión social, sentimientos e actitudes positivos y preocupación por el medio ambiente. A fin de evaluar el grado de asociación entre las respuestas de los administradores y los empleados se calculó el coeficiente de correlación Rho de Spearman. Los resultados permitieron identificar una red de conceptos asociados al concepto de responsabilidad social, tal como es previsto en una de las teorías de formación de conceptos: la visión teórica.

Palabras claves: Formación de conceptos. Discapacitados. Inclusión social. Responsabilidad social.

O presente trabalho buscou avaliar a concepção de responsabilidade social (RS) de gestores e empregados de algumas empresas do Estado de São Paulo que participam da Política Nacional para a Integração da Pessoa com Deficiência.
A RS tornou-se um tema recorrente no âmbito das organizações ao longo da última década e tem assumido quatro correntes principais: (1) teorias instrumentais, em que as corporações são vistas como um instrumento para a criação de riqueza e sua função social 
Assim, na prática, a responsabilidade social das

empresas ou das corporações apresenta quatro dimensões: uma relativa aos benefícios, outra ao desempenho político, uma terceira às demandas sociais e uma quarta, ligada aos valores éticos (Garriga \& Melé, 2004). é apenas um meio para gerar riqueza, (2) teorias políticas, que se preocupam com o poder das corporações na sociedade e o uso responsável desse poder na área política, (3) teorias integrativas, em que a empresa está focada na satisfação de demandas sociais e (4) teorias éticas, com base na ética das responsabilidades sociais da empresa para com a sociedade. Assim, na prática, a responsabilidade social das empresas ou das corporações apresenta quatro dimensões: uma relativa aos benefícios, outra ao desempenho político, uma terceira às demandas sociais e uma quarta, ligada aos valores éticos (Garriga \& Melé, 2004).

No Brasil, o movimento de valorização da responsabilidade social empresarial ganhou forte impulso na década de 90 por meio da ação de entidades não governamentais, de institutos de pesquisa e de empresas sensibilizadas para a questão. As enormes carências e as desigualdades sociais existentes em nosso país dão à responsabilidade social empresarial uma relevância ainda maior (Instituto Ethos, 2009).

\section{Responsabilidade social}

Apesar de sua grande importância, ainda não se chegou a um consenso a respeito do que seja RS. A história moderna do conceito iniciase nos anos 50, com a publicação do livro Social Responsabilities of the Businessman, de Howard Bowen, em 1953 (Carroll, 1999; Garriga \& Melé, 2004). Segundo Carroll, o trabalho de Bowen assentava-se na crença de que as grandes empresas eram centros vitais de poder e decisão e de que as ações dessas empresas exerciam influência na vida dos cidadãos em muitos aspectos.

Nos anos 60, Clarence Walton, o mais importante pensador na área dessa época, ressalta que a responsabilidade social "reconhece a intimidade das relações entre a corporação e a sociedade, e percebe que tais relações devem ser mantidas em mente pelos administradores principais, assim como pelas corporações e os grupos relacionados que perseguem determinadas metas" (1967, p.18).

Na década de 70, predominaram definições como as de Eells e Walton (1974), ligadas a questões e princípios éticos adotados pela empresa no que diz respeito a problemas de ordem social. Surge a ideia da empresa como um elo entre as sociedades, os indivíduos e o governo, como instrumento capaz de melhorar a qualidade de vida através do desenvolvimento econômico.

Nos anos 80, é introduzido o conceito de desempenho social corporativo (CSP) por Wartick e Cochran (1985), que consiste em um modelo tridimensional de integração entre a responsabilidade, a capacidade de resposta e os temas sociais.

Na década de 90, o conceito migrou, segundo Carroll (1999), para temas alternativos como os stakeholders, a teoria ética de negócios e a cidadania corporativa.

E, finalmente, no início do século XXI, segundo Garriga e Melé, renovou-se o interesse pela responsabilidade social, dessa vez ligado à cidadania corporativa e à sustentabilidade ambiental, como ilustram os trabalhos de Matten, Crane e Chapple (2003) e de Wood e Lodgson (2002), assim como pela consideração das diferenças individuais entre as pessoas (Rupp, 2011).

Essa multiplicidade e variedade de definições reflete as imprecisões e as dúvidas dos muitos estudiosos do assunto acerca do real significado do termo. As diferentes definições e a constante procura por entender o que seja RS levam-nos a perguntar sobre as representações mentais subjacentes a esse conceito, o que implica indagar: Que forma assume em nossa mente o conceito de responsabilidade social? Que atributos ou 
características são comumente atribuídos a ele pelos sujeitos durante o processo de sua formação?

\section{Conceitos: uma breve revisão teórica}

A pesquisa psicológica sobre conceitos desenvolveu, ao longo de quase um século de estudos e pesquisas, quatro grandes concepções sobre a forma pela qual os conceitos são representados na mente humana: a visão clássica, a visão prototípica ou probabilística, a visão dos exemplares e, por último, a visão teórica (Lomônaco, Caon, Heuri, Santos, \& Franco, 1996; Lomônaco, 1997).

A concepção clássica considera que os conceitos são formados por meio da abstração de atributos comuns a todos os membros de um grupo de coisas, eventos ou pessoas. A representação de um conceito consiste em uma descrição sumária de uma classe inteira. Os atributos definidores de um conceito são individualmente necessários e conjuntamente suficientes para definilo, e estão necessariamente incluídos nos subconjuntos desses conceitos (Lomônaco et al., 1996).

A visão prototípica, ao contrário, rejeita a noção de atributos definidores e introduz a de probabilidade de ocorrência. Segundo Lomônaco, de Paula, de Mello e Almeida (2001), supõe-se que as pessoas, ao entrarem em contato com múltiplos exemplos dos objetos, abstraem as correlações de atributos que ocorrem com maior frequência e assim, formam uma representação mental sumária da categoria que é denominada protótipo. Ou seja, tal como uma medida de tendência central, o protótipo seria como uma média de todos os exemplos encontrados pelo indivíduo. Uma vez formado, seria utilizado para decidir a inclusão/exclusão de membros na categoria: assim, se algum exemplo é suficientemente similar ao protótipo, ele seria classificado como pertencente a essa categoria, e, ao contrário, se um novo objeto é bastante dissimilar ao protótipo, não seria considerado um exemplo da categoria.

A visão dos exemplares afirma que os conceitos são representados por exemplos individuais em vez de, como pressupõe a visão prototípica, por um sumário de características mais frequentes. Supõe-se que os exemplos desempenhem um papel predominante na categorização, presumivelmente porque são mais acessíveis do que a representação sumária. Assim, o indivíduo, ao encontrar diferentes exemplos de um mesmo conceito, seleciona um ou alguns exemplos que considera mais representativos e, da mesma forma que na visão prototípica, utiliza-se desse ou desses exemplares para decidir a inclusão ou a exclusão de novos exemplos na categoria (Lomônaco et al., 1996).

A visão teórica surgiu no domínio da Psicologia em meados da década de 80, embora suas ideias já estivessem presentes na Filosofia há muitos anos (Oliveira, 1999). Essa visão começou a desenvolver-se a partir das limitações identificadas nas teorias anteriores (visões clássica, prototípica e dos exemplares), principalmente a de considerar a similaridade como o fator mais importante para explicar o processo de formação de conceitos. As primeiras e mais severas críticas foram publicadas em um artigo de Murphy e Medin, em 1985, no qual os autores apontam o fator similaridade como flexível ou amplo demais para delimitar a formação dos conceitos (Lomônaco, Cazeiro, \& Ferreira, 2006). Dependendo do critério utilizado para determinar o que deve e o que não deve ser considerado similar, agrupamentos ou categorizações muito distintos podem ser criados. Por exemplo: um carro e uma árvore são objetos sólidos, ocupam um lugar no espaço, são mais pesados do que uma pessoa, são constituídos por átomos, têm as letras $\underline{\text { a }}$ 
o e $r$ na língua portuguesa, são objetos úteis, etc. Não obstante, parece não haver em nenhuma cultura conhecida uma categoria que inclua esses dois tipos de coisas, embora não seja pequeno o grau de aspectos em que eles apresentam similaridade.

Em face da dificuldade das teorias de conceitos anteriores de explicar porque temos determinados conceitos e não outros quaisquer (a questão da coesão conceitual), a visão teórica parece oferecer uma explicação alternativa.

Os conceitos, para a visão teórica, nunca podem ser considerados isoladamente, pois estão sempre relacionados uns com os outros, formando uma rede conceitual. É a essa rede que se dá o nome de teorias. Em função do seu caráter de rede, ao modificar os atributos de qualquer um dos conceitos que a compõem, toda ela é alterada. Em uma rede conceitual, os conceitos podem ser entendidos como os nódulos, e as relações, como os fios que ligam um nódulo ao outro. Existe um equilíbrio entre os conceitos da rede, mas, a qualquer momento, esse equilíbrio pode ser rompido se qualquer um dos conceitos (ou atributos dos conceitos) for modificado pela experiência do sujeito. Keil (1989) denomina homeostase causal o fator que mantém a rede em equilíbrio.

Para a visão teórica, a inclusão e a manutenção de um conceito em uma categoria dependem da relação que estabelece com os demais. Sendo assim, os conceitos que formam uma rede devem estar fortemente relacionados. Essas relações provêm das experiências do indivíduo, adquiridas pelo senso comum ou pelo ensino escolar. Cada vez que o sujeito vivencia uma nova situação de aprendizagem, a rede conceitual envolvida pode ter seu equilíbrio rompido, o que daria origem a uma reorganização da estrutura.
Em uma pesquisa com estudantes de fisioterapia, Lomônaco, Cazeiro e Ferreira investigaram mudanças nos conceitos de deficiência e reabilitação entre os alunos do primeiro e do quarto anos de um curso de graduação. Verificou-se que os conceitos dos estudantes do primeiro ano eram bastante similares aos das pessoas leigas, ressaltando predominantemente aspectos humanísticos, enquanto os dos alunos do último ano, certamente em função de seu percurso acadêmico, salientavam mais os atributos de caráter técnico-científico. Os autores puderam também verificar que houve uma coerência na rede de atributos ou de características evocados pelos sujeitos, tanto no conceito de deficiência quanto no de reabilitação, em ambas as séries escolares, indicando a ocorrência do fenômeno da homeostase causal na rede de atributos associados aos conceitos. Em outras palavras, os atributos associados a ambos os conceitos constituíam um todo coerente, convergiam para a mesma direção, indicavam um mesmo sentido e não apresentavam contradição ou oposição entre eles.

Neste trabalho, que visa a avaliar os atributos que fazem parte de rede conceitual na qual se acha inserida o conceito de responsabilidade social, procurar-se-á verificar, além dos atributos em tela, como tais atributos se organizam, visando identificar a ocorrência da homeostase causal, responsável, segundo a visão teórica, pela coesão conceitual.

\section{Método}

\section{Sujeitos}

A amostra selecionada por conveniência foi constituída por 57 sujeitos, divididos em dois grupos denominados gestores (grupo 1) e empregados (grupo 2), ambos trabalhadores de diferentes empresas privadas de grande porte da capital paulista e do Município de São José dos Campos, no interior do Estado 
de São Paulo. O grupo gestores foi formado por 19 profissionais de recursos humanos, sendo 10 do sexo masculino e 9 do sexo feminino. O grupo empregados foi formado por 38 profissionais com deficiência, sendo 24 do sexo masculino e 14 do sexo feminino.

Escolhemos esse público para a amostragem pelo fato de a inclusão de pessoas com deficiência no mercado de trabalho estar frequentemente associada à responsabilidade social das empresas. Além disso, a contratação de pessoas com deficiência é determinada por lei (art. 93 da Lei no 8.213/91), e tem como um de seus objetivos reduzir a desvantagem histórica de acesso ao mercado de trabalho, promovendo oportunidades de equidade social para essa população (Brasil, Ministério do Trabalho e Emprego, 2007). O tipo de deficiência não foi adotado como critério para inclusão dos sujeitos nesse grupo, que foi constituído pessoas com deficiência física, visual (baixa visão) ou auditiva (moderada). Os profissionais de recursos humanos foram selecionados por entendermos que são os responsáveis pela tarefa de contratar e de acompanhar os candidatos no preenchimento das vagas determinadas pela lei acima referida.

\section{Material}

Cada sujeito utilizou um bloco de papel com duas páginas (cada página correspondia à metade de uma folha de papel sulfite do tamanho A4). Na parte superior da primeira folha, o sujeito deveria informar alguns dados pessoais como: nome da empresa em que trabalha, idade, sexo, tempo de trabalho na empresa e grau de escolaridade.

Na parte inferior dessa mesma página, estavam impressas as seguintes instruções:

Estamos interessados em conhecer as ideias comumente atribuídas ao termo responsabilidade social. Assim sendo, venho solicitar sua colaboração neste trabalho de pesquisa.

Na parte superior da página seguinte, você encontrará as palavras RESPONSABILIDADE SOCIAL. O que lhe pedimos é muito simples: leia o termo e, a seguir, no período de um minuto e meio, escreva no espaço em branco todas as características que lhe vierem à mente diante desse estímulo. A sua primeira impressão é muito importante, portanto, você não deve se preocupar em saber se suas respostas são adequadas ou não. O que nos interessa são suas evocações ou associações diante do estímulo apresentado.

Muito obrigado por sua colaboração.

Na parte superior da segunda folha, estavam impressas, em letras maiúsculas e em formato negrito e centralizadas, as palavras RESPONSABILIDADE SOCIAL. Todo o restante dessa página estava em branco.

\section{Procedimento}

A coleta foi realizada nos meses de outubro e novembro de 2008 após o consentimento da direção e/ou gerência de cada empresa.

Alguns dos pesquisadores que compõem o grupo de autores deste trabalho aplicaram o instrumento em um determinado número de sujeitos, que foram divididos em pequenos grupos ou responderam individualmente, de acordo com as possibilidades de cada empresa. Os sujeitos também foram informados a respeito do objetivo da pesquisa e de sua participação, que seria voluntária. Nenhum deles se recusou a participar.

Ao iniciar a aplicação do instrumento, as instruções da primeira página foram lidas e as dúvidas sanadas. Logo após, os dados pessoais foram informados. Em seguida, iniciou-se a tarefa de escrever, em um período de 90 segundos, as associações evocadas pelas palavras RESPONSABILIDADE SOCIAL. 
Terminada a aplicação, as folhas foram recolhidas.

\section{Resultados}

\section{Criação das categorias}

A partir dos dados coletados, todas as respostas dos sujeitos foram digitadas e organizadas em ordem alfabética, separadamente, para o grupo de empregados e gestores. Foi identificado, também, o número de vezes em que a mesma resposta foi evocada por diferentes sujeitos do mesmo grupo.

Em um segundo momento, a tarefa de cada pesquisador foi a de ler diversas vezes as respostas arroladas com o objetivo de identificar aspectos comuns que permitissem criar categorias. Nessa fase, as categorias foram criadas individualmente pelos pesquisadores.

Em um terceiro momento, os pesquisadores, coletivamente, procuraram chegar a um consenso sobre que categorias deveriam ser criadas, que denominações lhes seriam atribuídas e quais respostas deveriam ser nelas incluídas. As respostas não abrangidas por nenhuma das categorias elaboradas foram agrupadas na categoria outras respostas.

A fim de evitar a criação de categorias com um número muito reduzido de respostas, adotouse como critério para a criação de categorias que cada uma delas englobasse, no mínimo, $5 \%$ das respostas de cada um dos grupos

As categorias elaboradas e a descrição do seu significado são apresentadas abaixo:

Preocupação com o ambiente: engloba os termos referentes à responsabilidade do indivíduo para com os recursos naturais (exemplos: consumo responsável, preservar a natureza, reciclagem, verde).

Solidariedade (cooperação): abrange as respostas indicativas de ajuda (exemplos: ajuda ao próximo, fraternidade, ajuda para o crescimento profissional, companheirismo).

Inclusão social: inclui respostas que mencionam igualdade de direitos e oportunidades sociais entre pessoas com e sem deficiência (exemplos: acesso igualitário, igualdade, justa oportunidade sobre o trabalho, incluir).

Sentimentos e atitudes positivos: agrupa termos referentes a sentimentos e atitudes positivos (exemplos: amizade, carinho, lealdade, tratar igual, saber entender).

Respeito: abrangem termos que mencionam respeito entre as pessoas, respeito aos direitos e aos espaços alheios (exemplos: respeito ao próximo, respeitar direitos, respeito ao espaço de cada um, respeitar as diferenças).

Compromisso social: refere-se a respostas relativas ao comprometimento e à responsabilidade do indivíduo para com a sociedade, o próximo e o trabalho (exemplo: cumprir as obrigações no trabalho, ser responsável, responsabilidade com a sociedade, compromisso).

Coletividade: inclui associações que expressam colaboração entre pessoas e trabalho em grupos (exemplos: cooperativismo, comunidade, trabalho em equipe, complementaridade).

Outras: respostas que não foram abrangidas pelas categorias criadas.

Após as categorias terem sido elaboradas, foram utilizadas para agrupar as respostas dos sujeitos.

\section{Análise dos resultados}

Na Tabela 1, estão apresentadas as frequências, a porcentagem e a ordenação das respostas de empregados e gestores em cada uma das categorias criadas. 
Tabela 1. Frequência, porcentagem e ordenação das respostas de empregados e gestores por categorias

\begin{tabular}{|c|c|c|c|c|c|c|c|}
\hline \multirow{2}{*}{ Categor } & \multirow[b]{2}{*}{ Frequência } & \multicolumn{2}{|l|}{ Empregados } & \multicolumn{2}{|c|}{ Gestores } & \multirow[b]{2}{*}{ Posto } & \multirow[b]{2}{*}{ Porcentagem tota } \\
\hline & & Porcentagem & Posto & Frequência & Porcentagem & & \\
\hline Inclusão social & 25 & $19,8 \%$ & $1^{\circ}$ & 13 & $21,6 \%$ & $2^{\circ}$ & $20,4 \%$ \\
\hline $\begin{array}{l}\text { Sentimentos } \\
\text { e atitudes positivos }\end{array}$ & $s^{21}$ & $16,6 \%$ & $2^{\circ}$ & 14 & $23,3 \%$ & $1^{\circ}$ & $18,8 \%$ \\
\hline Solidariedade & 18 & $14,2 \%$ & $3^{\circ}$ & 6 & $10 \%$ & 50 & $12,9 \%$ \\
\hline Outras & 15 & $11,9 \%$ & $4^{\circ}$ & 4 & $6,6 \%$ & $6^{\mathrm{o}}$ & $10,2 \%$ \\
\hline Preocupação & & & & & & & \\
\hline com o ambiente & 13 & $10,3 \%$ & $5^{\circ}$ & 12 & $20 \%$ & $3^{\circ}$ & $13,4 \%$ \\
\hline $\begin{array}{l}\text { Coletividade } \\
\text { Compromisso }\end{array}$ & 12 & $9,5 \%$ & $6^{0}$ & 2 & $3,3 \%$ & 70 & $7,5 \%$ \\
\hline social & 12 & $9,5 \%$ & $6^{\circ}$ & 7 & $11,6 \%$ & $4 \mathrm{O}$ & $10 \%$ \\
\hline Respeito & 10 & $7,9 \%$ & $8^{\circ}$ & 2 & $3,3 \%$ & $8^{\mathrm{o}}$ & $6,4 \%$ \\
\hline Total & 126 & $100 \%$ & & 60 & $100 \%$ & & $100 \%$ \\
\hline
\end{tabular}

Considerando-se os dados como um todo (última coluna da Tabela 1), verifica-se que o maior número de respostas concentrou-se em três categorias - inclusão social, sentimentos e atitudes positivos, preocupação com o ambiente - que, em conjunto, concentraram um pouco mais da metade $(52,6 \%)$ do total das respostas. Por outro lado, os menores percentuais também se concentraram em três categorias - respeito, compromisso social, coletividade - que, juntas, compreendem aproximadamente um quarto do total das respostas (23,9\%). Essa concentração repete-se quando são considerados isoladamente os dados dos empregados - 50,6\% e 26,9\% respectivamente para as três categorias mais e menos escolhidas -, mas apresenta algumas diferenças no grupo gestores. Nesse grupo, as três categorias mais escolhidas foram sentimentos e atitudes positivos, inclusão social e preocupação com o ambiente, que agrupam quase dois terços das respostas $(64,9 \%)$. As três menos escolhidas - outras, coletividade e respeito - concentraram apenas $13,2 \%$ das respostas.

Os resultados foram analisados pela estatística do Qui-quadrado para uma amostra, uma vez que os dados de empregados e gestores foram considerados conjuntamente. Essa prova é adequada para analisar situações em que os dados são agrupados em duas ou mais categorias e permite comprovar se existe diferença significante entre o número observado de respostas em determinada categoria e o respectivo número esperado com base na hipótese de nulidade (Siegel, 1981), ou, como salienta Rodrigues (1975), em todas as situações nas quais lidamos com a frequência em que um fenômeno ocorre e com categorias distintas, o Teste do Qui-quadrado é utilizável.

A análise dos dados realizada separadamente para empregados e gestores não permitiu rejeitar a hipótese de nulidade ao nível de $p<0,05$ nem para a amostra de empregados nem para a de gestores. Assim sendo, procedeu-se ao cálculo do qui-quadrado para a amostra como um todo. Os valores encontrados $\left(n=186 ;\right.$ g. I. $=7 ; X^{2}$ crítico $=24,32 ; X^{2}$ observado $=25,28 ; p$ $<0,001)$ permitem rejeitar a hipótese nula com um alto grau de probabilidade.

A fim de avaliar o grau de associação entre os dois conjuntos de escores - as respostas dos 
gestores e as dos empregados - as categorias foram ordenadas em ordem decrescente e foi calculado o coeficiente de correlação posto-ordem de Spearman. Essa estatística permite avaliar o grau de associação entre duas variáveis medidas pelo menos, em escala ordinal, desde que "...os objetos ou indivíduos em estudo possam ser dispostos em postos em duas séries ordenadas" (Siegel \& Castellan, 2006, p. 266).

O coeficiente posto-ordem Rô de Spearman foi de 0, 066, e o nível de significância foi de $\mathrm{p}=0,438$, ou seja, a correlação de postos entre empregados e gestores é baixa e não significante.

\section{Discussão}

Uma primeira análise e a discussão dos resultados serão feitas para a amostra como um todo (ver a última coluna da Tabela 1) visando a verificar se é possível postular a ocorrência da homeostase causal, tal como definida por Keil (1989). A seguir, será analisado o grau de concordância entre as respostas de gestores e empregados (ver a $2^{a}$. e a $5^{a}$. colunas da mesma tabela), a fim de identificar convergências e divergências em seus resultados.

A categoria que incluiu o maior número de respostas foi inclusão social, com 20,4\% do total das respostas. Termos como acesso igualitário, oportunidade justa ao trabalho, igualdade, inclusão e outros similares, associados à responsabilidade social, parecem indicar que, na visão de nossos sujeitos, esta implica igualdade de direitos e diminuição das grandes diferenças socio-econômicas que caracterizam a sociedade brasileira. E, talvez, seja esse aspecto referente à desigualdade social um dos fatores explicativos dessa alta porcentagem de respostas evocadas pelo termo, uma vez que ele é frequentemente associado a esforços no sentido de melhorar as condições da sociedade e tornar o mundo um local mais justo e humano.

A segunda categoria com maior número de respostas foi sentimentos e atitudes positivos, que abrangeu quase um quinto das respostas $(18,8 \%)$. Expressões tais como amizade, carinho,_lealdade, saber entender, etc. parecem indicar que a responsabilidade social é vista de maneira positiva e, até mesmo, afetiva, contrariando uma expectativa do senso comum de que ela não poderia ser vista dessa maneira, uma vez que implica, em muitos casos, uma obrigatoriedade legal da qual os gestores não podem se livrar sob pena de punição. $\mathrm{Na}$ verdade, quando os resultados são considerados separadamente, a porcentagem de respostas dos gestores (23,3\%) é ainda maior do que a dos empregados.

Preocupação com o meio ambiente, categoria que agrupou $13,4 \%$ das respostas, foi identificada em respostas tais como verde, consumo responsável, preservação da natureza,_reciclagem e outros termos similares. É possível pensar que tal preocupação tenha algo a ver com o fato de as empresas industriais serem frequentemente acusadas de agredir a natureza, o que leva a sérios problemas ambientais. É nesse sentido que a sociedade em geral e as agências reguladoras em especial reivindicam das empresas responsabilidade social, chamando a atenção para a necessidade de elas se preocuparem seriamente com os danos ambientais que seus produtos e/ou a sua fabricação podem estar causando ao meio ambiente. É interesse das empresas associarem a sua marca e os seus produtos à ideia de preservação ambiental, uma vez que a empresa gostaria de ser lembrada como ambientalmente correta. Além disso, uma ação ambientalmente incorreta pode prejudicar os interesses econômicos das empresas, pois essa pode ser exigida para a venda de produtos. Um claro exemplo é a compra de madeira da Amazônia sob condição de preservação 
da floresta. Nesse sentido, é bastante compreensível que essa tenha sido uma associação bastante evocada pelos gestores (3․ posto), em uma porcentagem superior ao posto dos empregados (5ㅇ․ posto).

A categoria solidariedade, representada por palavras como ajuda ao próximo, fraternidade, companheirismo, etc., sugere que o conceito de responsabilidade social, para nossos sujeitos, está associado à ideia de cooperação e de ajuda mútua entre pessoas. Considerando-se que parte de nossos sujeitos - os empregados - eram pessoas deficientes que, graças a dispositivos legais, conseguiram ser empregadas, não é de se estranhar a evocação/associação de termos tais como os acima exemplificados ao conceito de responsabilidade social. Também pode ter ocorrido de a pessoa com deficiência inadequadamente considerar sua contratação como um ato de solidariedade, em vez de sentir que foi contratada pelas suas capacidades e que é remunerada de acordo com seu desempenho e sua qualificação.

A proximidade entre os conceitos compromisso social e responsabilidade social ajuda a explicar a criação dessa categoria, uma vez que atributos como responsabilidade, compromissos e obrigações parecem intuitivamente ser partes integrantes do conceito mais amplo de responsabilidade social.

No tocante à categoria coletividade $(7,5 \%$ das respostas), associações tais como cooperativismo, trabalho em equipe e comunidade, indicativas da reunião de esforços para se chegar a um objetivo comum, podem ser resultado da percepção de que as mudanças e/ou tarefas que implicam responsabilidade social (e não meramente pessoal) ultrapassam em muito a possibilidade de ação de um único indivíduo, requerendo necessariamente um trabalho cooperativo para que as mudanças exigidas ocorram ou para que as tarefas possam ser completadas.

Finalmente, a categoria respeito, ilustrada por associações tais como respeito ao próximo, respeitar direitos, respeitar as diferenças, etc., foi a que abrangeu o menor número de respostas $(6,4 \%$, apenas um pouco acima do critério estabelecido para a formação de categorias). Uma possível explicação para esse reduzido número de respostas é o de que tais associações ocorreram quase que exclusivamente entre os empregados (dez respostas nesse grupo contra apenas duas no grupo de gestores), o que, na verdade, é um dado significativo. Como interpretar esse dado? Como já mencionado, a nossa amostra de empregados foi composta exclusivamente por sujeitos deficientes. É razoável pensar que, em face de suas deficiências, nossos sujeitos tenham vivenciado muitos episódios nos quais se sentiram desrespeitados em sua dignidade. A admissão a um emprego, talvez o primeiro de suas vidas, que lhes propiciou melhora da autoestima e certa independência financeira, pode ter feito com que eles tenham se sentido respeitados pela comunidade familiar e profissional, daí a evocação de termos referentes ao respeito entre pessoas e daí o porquê de tais evocações terem ocorrido predominantemente no grupo de empregados.

Como se pode depreender das considerações feitas, as respostas, tomadas como um todo, apresentam, pelo menos, um aspecto comum: seu caráter positivo, afetivo e construtivo. O termo responsabilidade social evocou nos sujeitos respostas indicativas de respeito, afeto positivo, solidariedade, trabalho em equipe e preocupação com a natureza, ou seja, os atributos comumente relacionados ao conceito de responsabilidade social convergem para um mesmo sentido ou direção, não havendo atributos contraditórios entre si, como seria o caso se tivéssemos identificado simultaneamente sentimentos 
positivos e negativos. Entendendo-se conceito nos termos postulados pela visão teórica, como uma rede constituída pelo conceito e por suas relações e/ou ligações com outros conceitos, nossos resultados nos levam a postular/acreditar que a rede da qual faz parte o conceito de responsabilidade social mantém-se unida em função do fenômeno que Keil denominou homeostase causal. Em outras palavras, em função das relações causais existentes entre os conceitos, a estrutura se mantém coesa e em equilíbrio. $\mathrm{E}$, uma vez que os diferentes atributos de um mesmo conceito se nos apresentam-se altamente inter-relacionados, é impossível mudar um atributo sem afetar os outros que fazem parte dessa rede conceitual (Lomônaco, Cazeiro, \& Ferreira, 2006).

De acordo com a visão teórica, apenas a definição pública ou oficial de um conceito diz muito pouco sobre o que ele realmente significa ou como é considerado privadamente pelo sujeito, ou ainda, como é representado na sua mente. O significado denotativo de um conceito geralmente é muito pobre quando considerado isoladamente. Somente quando são acrescentados a esse tipo de significado os aspectos conotativos, isto é, os afetos, os valores e as crenças que são comumente associadas a esse conceito particular por uma determinada população, é que poderemos obter uma compreensão mais completa do que esse conceito realmente significa para o indivíduo. Foi essa a finalidade ou o objetivo do presente estudo, que se utilizou de um instrumento capaz de sugerir os possíveis componentes da rede conceitual na qual o conceito de responsabilidade social está inserido.

Concluída essa discussão dos dados da amostra total de sujeitos, será feita uma análise em termos de grupos a fim de identificar as eventuais particularidades ou especificidades de cada um dos grupos. Como visto, a correlação entre as respostas dos gestores e as dos empregados revelouse baixa e não significante, indicando não existir um alto grau de concordância entre os dois grupos de sujeitos no que se refere aos aspectos ou atributos mais frequentemente associados ao conceito de responsabilidade social.

Não obstante essa discrepância geral, uma análise da Tabela 1 revela que, na categoria sentimentos e atitudes positivos, ambos os grupos apresentaram posições bastante próximas $-1^{0}$ posto para gestores e $2^{\underline{0}}$ para empregados, indicando uma predisposição favorável por parte de nossos sujeitos no tocante ao conceito de responsabilidade social. Tal resultado não chega a surpreender, visto que conceitos tais como responsabilidade social e assemelhados (compromisso, responsabilidade, dever, seriedade, etc.) são comumente apresentados em todos os meios de comunicação de massa sob uma luz positiva, como qualidades ou virtudes que deveriam ser inculcadas nos indivíduos, por meio do processo de socialização, para formar cidadãos responsáveis.

Algo similar ocorreu com a categoria inclusão social, que agrupou o maior número de respostas no grupo empregados e situouse em segundo lugar no grupo gestores. Como entender tal resultado? No tocante aos empregados, nossa hipótese é a de que ele possa ser explicado em função do tipo de participante do estudo, pessoas com algum tipo de deficiência e que, ao longo de suas vidas, certamente experenciaram dificuldades de serem aceitas tanto nos diferentes espaços de convívio social quanto ou, talvez, principalmente, no mercado de trabalho. Daí a sensibilidade dessas pessoas ao aspecto inclusão social como componente do conceito de responsabilidade social. No tocante aos gestores, é bastante evidente que o objetivo da Política Nacional para Integração da Pessoa com Deficiência é o de incluir o deficiente no mercado de trabalho 
e, disso, certamente, estão conscientes os profissionais de recursos humanos.

Preocupação com o ambiente situou-se no $3^{\circ}$ posto entre os gestores e no $5^{\circ}$ posto entre os empregados. Aparentemente, a melhor colocação dos gestores reflete a preocupação amplamente disseminada nas empresas com a proteção do meio ambiente, quer em função das múltiplas campanhas na mídia em prol da sustentabilidade ambiental, quer em função das punições (multas, por exemplo) a que as empresas estão sujeitas pelo descumprimento das normas que regem a matéria. Além disto, associar o nome da empresa a ações que visam a proteger o meio ambiente é uma prática amplamente disseminada no meio empresarial. Dessa forma, a associação do conceito de responsabilidade social a preocupações com o meio ambiente não chega a surpreender. Da mesma maneira, não surpreende que, entre os empregados, ela não tenha merecido a mesma atenção que a dispensada pelos gestores.

A classificação da categoria compromisso social, embora com uma diferença de dois postos entre empregados e gestores, $6^{0}$ posto entre os empregados e 4․ entre os gestores, indica preocupações similares, embora não com a mesma intensidade, com o comprometimento e a responsabilidade do indivíduo para com a sociedade, o próximo e o trabalho. Na verdade, pensamos não haver boas razões para que empregados e gestores não manifestem essas mesmas preocupações.

Mais difícil de entenderéa posição da categoria respeito entre os grupos. Intuitivamente, parece-nos que esse componente deveria merecer maior preocupação por parte do grupo de empregados, visto que não é incomum que pessoas participantes desse grupo sejam desrespeitadas em seus direitos e em seus espaços sociais. Não obstante, não foi isso o que ocorreu, uma vez que esse componente foi o menos mencionado de todos, vindo a ocupar o último posto. Que hipóteses poderiam ser aventadas para explicar esse resultado aparentemente tão contraintuitivo? Ocorre-nos que talvez nossos sujeitos não tenham se sentido desrespeitados em seus locais de trabalho. Afinal de contas, foram efetivamente selecionados para desempenhar funções na empresa em função de suas capacidades e habilidades e não por mera solidariedade e/ou piedade. Por outro lado, o fato de serem financeiramente independentes ou dependerem menos de assistência financeira por parte de suas famílias pode também ter contribuído para que sejam mais respeitados em seu ambiente social e familiar. Dessa forma, o atributo respeito pode não ter ocorrido ou não ter sido associado à responsabilidade social pela maior parte de nossos sujeitos.

\section{Considerações finais}

Em resumo, embora os resultados encontrados pareçam aos seus autores retratar plausivelmente a rede conceitual do conceito de responsabilidade social, é preciso não esquecer algumas limitações deste trabalho que impedem uma ampla generalização de suas conclusões.

Em primeiro lugar, é preciso atentar para o fato de que o trabalho de elaboração de categorias implica necessariamente algum grau de subjetividade. Muito embora as categorias elaboradas e suas denominações tenham sido amplamente discutidas entre os autores deste estudo, fossem outros os autores e, possivelmente, teríamos outras denominações para as mesmas categorias e/ou outras categorias não constantes deste trabalho.

Outro aspecto merecedor de atenção referese ao pequeno número de sujeitos da amostra e ao fato de o estudo ter sido feito em uma única região do país. Amostras maiores e mais 
diversificadas poderiam levar a resultados com maior poder de generalização.

Acreditamos, todavia, que a publicação deste estudo poderá servir para divulgar o instrumento de coleta de dados e o procedimento para coletá-los e analisálos, sugerindo possíveis agrupamentos em categorias. Nesse sentido, novos trabalhos, que possibilitem avaliar o grau de confiança e de generalidade dos nossos dados, fazem-se necessários.

\section{José Fernando Bitencourt Lomônaco}

Mestre em Psicologia Escolar e do Desenvolvimento Humano pela Universidade de São Paulo, Professor Associado no Instituto de Psicologia da Universidade de São Paulo, SP - Brasil.

E-mail: jfblusp@usp.br

\section{Caio Parada Cabral}

Mestre em Psicologia Escolar e do Desenvolvimento Humano pela Universidade de São Paulo, Brasil(2011), Professor do Centro Universitário das Faculdades Metropolitanas Unidas, São Paulo - SP - Brasil.

E-mail: caio.cabral@usp.br

\section{Carla Ulasowicz}

Mestre em Psicologia Escolar e do Desenvolvimento Humano pelo Instituto de Psicologia da Universidade de São Paulo, Trabalha no Grupo de Estudo e Pesquisa Em Educação Física Escolar, São Paulo - SP - Brasil. E-mail: carla.ulasowicz@hotmail.com

\section{Patrícia Thomasio Quinelato}

Mestre em Linguística Aplicada e Estudos da Linguagem pela Pontifícia Universidade Católica de São Paulo,Professora de Ensino Fundamental e Médio de I do CEU Pêra Marmelo,São Paulo - SP - Brasil. E-mail: teacherquinelato@terra.com.br

\section{Paula Alejandra Boero Villagran}

Doutoranda do Instituto de Psicologia da Universidade de Sao Paulo, São Paulo - SP - Brasil.

E-mail: pboero@usp.br

\section{Tereza Cristina Rangel Credidio Zampieri}

Consultora FUNDAP, Especialista em Psicologia Organizacional e do Trabalho pelo Conselho Federal de Psicologia, Brasília - DF - Brasil.

E-mail: cristina.credidio@hotmail.com

\section{Endereço para envio de correspondência:}

Instituto de Psicologia - Av. Prof. Mello Moraes, 1721

Cidade Universitária, São Paulo - SP - Brasil. CEP 05508-030

Recebido 10/11/2009, 1a Reformulação 24/10/2011, Aprovado 6/1/2012. 
Bowen, H. R. (1953). The social responsibilities of the businessman. New York: Harper Row.

Brasil. Ministério do Trabalho e Emprego. (2007). A inclusão de pessoas com deficiência no mercado de trabalho. Brasília, DF: TEM, SIT, DEFIT.

Carroll, A. B. (1999). Social corporate responsibility: Evolution of a definitional construct. Business \& Society, 38(3), 268-295.

Eells, R., \& Walton, C. (1974). Conceptual foundations of business 3rd. Burr Ridge, IL:Irwin.

Garriga, E., \& Melé, D. (2004). Corporate social responsibility theories: Mapping the territory. Journal of Business Ethics, $53,51-71$.

Instituto Ethos. Responsabilidade social no Brasil. Recuperado em 29 julho, 2009, de http://www.ethos.org.br/docs/conceitos_ praticas/indicadores/responsabilidade/contexto_brasileiro.asp

Keil, F. C. (1989). Concepts, kinds, and cognitive development. Cambridge, MA: MIT Press.

Lomônaco, J. F. B., Caon, C. M., Heuri A. L., Santos, D. M., \& Franco, G. T. (1996). Do característico ao definidor: um estudo exploratório sobre o desenvolvimento de conceitos. Psicologia: Teoria e Pesquisa, 12(1), 51-60.

Lomônaco, J. F. B. (1997). A natureza dos conceitos: visões psicológicas. Tese de Livre-docência, Instituto de Psicologia, Universidade de São Paulo, São Paulo, SP.

Lomônaco, J. F. B., de Paula, F. V., de Mello, C. B., \& Almeida, F. A. (2001). Desenvolvimento de conceitos: o paradigma das transformações. Psicologia: Teoria e Pesquisa, 17(2), 161-168.

Lomônaco, J. F. B., Cazeiro, A. P. M., \& Ferreira, A. (2006).
Concepções de deficiência e reabilitação: um estudo exploratório com graduandos de fisioterapia. Psicologia Escolar e Educacional, 10(1), 83-97.

Matten, D., Crane, A., \& Chapple, W. (2003). Behind the mask: Revealing the true face of corporate citizenship. Journal of Business Ethics, 45(1-2), 109-120.

Oliveira, M. B. (1999). Da ciência cognitiva à dialética. São Paulo: Discurso Editorial.

Rodrigues, A. (1975). A pesquisa experimental em psicologia e educação. São Paulo : Vozes.

Rupp, D. E. (2011). An employee-centered model of organizational justice and social responsibility. Organizational Psychology Review, 1(1), 72-94.

Siegel, S. (1981). Estatística não-paramétrica para as ciências do comportamento. São Paulo: Mc Graw-Hill do Brasil.

Siegel, S., \& Castellan, J. (2006). Estatística não-paramétrica para as ciências do comportamento. Porto Alegre: Artmed.

Walton, C. C. (1967). Corporate social responsibilities. Belmont, CA: Wadsworth

Wartick, S. L., \& Cochran, P. L. (1985). The evolution of the corporate social performance model. Academy of Management Review, 10, 758-769.

Wood, D. J., \& Lodgson, J. M. (2002). Business citizenship: From individuals to organizations Business. Ethics Quarterly, Ruffin Series, 3, 59-94. 